\title{
Strategi Pemasaran Usaha Art Shop Lokal Di Desa Tegallalang Kabupaten Gianyar
}

Pande I Putu Angga Saputra a, 1, Saptono Nugroho a, 2

${ }^{1}$ putuanggacebok@gmail.com, ${ }^{2}$ saptono_nugroho@unud.ac.id

a Program Studi S1 Destinasi Pariwisata, Fakultas Pariwisata,Universitas Udayana, Jl. Dr. R. Goris, Denpasar, Bali 80232 Indonesia

\section{Abstract}

Art shop in Tegallalang is one of the businesses that were built by the community with a small capital as well as the livelihoods of local communities. The expansion of the art shop in Tegallalang causing the large number of tourists visiting Tegallalang, it is also supported by the presence of a tourism destination with the beauty of rice fields across the village that is known for its slender stones.

This research uses qualitative descriptive method, i.e. by doing interviews, observation, documentation, library studies and questionnaires. The technique of determination of informants used is purposive sampling technique and determination of the sample using the quota sampling and accidental sampling.

The result of this study show a marketing strategy that can be used by traders to face competition that is creating cultural tourism atttractions activities, introducing product manufacturing techniques to consumer, improving the ability in technologi, providing parking lots and transit places, providing facilities that can facilitate employes in work, improving quality or multiplaying product models, working with other in buying raw materials, make arrangement of prices agreement with other art shop and angage in English training.

Keywords: Businesses, local Art shop, marketing strategies, and competitiveness

\section{PENDAHULUAN}

Pariwisata merupakan salah satu sektor yang dapat meningkatkan pertumbuhan ekonomi Negara maupun masyarakat (Purnamasari 2016). Bali merupakan salah satu kawasan pariwisata yang terkenal dengan keindahan alam yang asri, keramah tamahan masyarakat dan memiliki beranekaragam budaya yang unik.

Perkembangan pariwisata di Bali menyebabkan pentingnya dalam menyediakan sektor penunjang pariwisata seperti: penginapan, tempat makan, atraksi wisata, akses jalan serta souvenir yang dapat dijadikan oleh - oleh saat wisatawan kembali ke daerah asalnya. Dengan adanya hal tersebut dapat menjadikan peluang bagi masyarakat dalam terbukanya lapangan pekerjaan dan dapat membuka usaha kecil. Salah satu usaha kecil dari masyarakat lokal yaitu membuka art shop (toko kecil) yang menjual berbagai hasil dari kerajinan tangan masyarakat.

Perkembangan art shop di Bali mulai sejak zaman kolonialisme Jepang dan Belanda, saat kepala kementrian bidang perekonomian pariwisata di Bali yaitu G. Koopman dan Jimmy (James Clarence) dari warga negara Belanda (Bayu (2009), dalam Palguna (2010)).

Pandy mendirikan sebuah art shop dimana dia meniru akuarium yang menjual cindramata atau souvenir dari hasil kerajinan seni rupa yang bermutu. Art shop di Bali pertama kali didirikan oleh Koopman yaitu seorang dari warga negara Belanda yang didirikan di Sindhu, Sanur dengan adanya pariwisata pada tahun 1930. Seiring berjalannya waktu di seluruh Bali terdapat 45 art shop pada tahun 1956 dan pada tahun 1970 merupakan puncak berkembangnya jumlah art shop dengan mengabaikan peraturan pemerintah terhadap larangan mendirikan sebuah bangunan di pinggir jalan (Vicker, 2013). Kata art shop berasal dari art dan shop, dimana art artinya seni atau kesenian yang juga berasal dari kerajinan dan shop yang berarti toko ataupun kios, jadi dapat disimpulkan art shop berarti sebuah toko atau kios yang menjual hasil kerajinan seni dari pengerajin ataupun seniman. Art shop merupakan salah satu penerapan usaha kecil pada suatu daya tarik wisata, seperti salah satunya di Desa Tegallalang.

Munculnya art shop di Tegallalang yaitu sekitar tahun 1990 yang didirikan oleh masyarakatl okal dari Tegallalang dan sekitarnya dengan menjual hasil kerajinan tangan masyarakat lokal yang berupa patung, bingkai, buah - buahan darikayu dan tulip. Pada tahun 2011 jumlah art shop di Tegallalangmeningkat, hingga mencapai 889 unit art shop, hal ini karena banyak 
wisatawan yang sudah mengenal adanya art shop di Tegallalang dan ditunjang dengan adanya destinasi wisata yaitu Ceking serta Tegallalang merupakan jalur penghubung (transit)

Meningkatnya jumlah art shop di Tegallalang dapat menyebabkan ancaman bagi pengusaha masyarakat lokal, hal ini karena masyarakat non local banyak yang membuka art shop di Tegallalang. Selain menjadi saing anantar art shop, dapat menyebabkan hilangnya nilai seni dari suatu produk dengan contoh membuat model produk yang sama tetapi dengan bahan yang berbeda dan lebih mudah dalam pengerjaannya serta harga bias lebih murah seperti bingakai dari kayu diubah mengunakan plastik atau fiber maupun resin.

Munculnya Masyarakat Ekonomi ASEAN (MEA) juga menjadikan ancaman bagi pengusaha kecil, karena akan munculnya pesaing dengan memiliki ekonomi yang tinggi dan kualitas yang lebih baik, serta strategi pemasaran yang sudah tersusun (Purnamasari 2016). Salah satu contohnya yaitu muncul pasar modern yang menjual jenis produk yang hampir sama dengan art shop local seperti: oleh - oleh Bali, Krisna, Cening Bagus dll.

Berdasarkan uraian diatas penelitian ini bermaksud untuk mengetahui Strategi Pemasaran usaha art shop lokal di Desa Tegallalang, Kabupaten Gianyar.

\section{KEPUSTAKAAN}

Dalam penelitian ini terdapat beberapa konsep yang digunakan untuk menganalisis data yang didapat dilapangan, yaitu:

Chandra (2002) mengemukakkan bahwa strategi pemasaran adalah suatu rencana dari perusahaan dalam menghadapi dampak dari berbagai program pemasaran terhadap permintaan produk di pasar sasaran yang akan ditentukan. Sedangkan menurut Kotler dan Amstrong (1997), strategi pemasaran adalah pola pikir pemasaran yang akan digunakan oleh unit bisnis untuk mencapai tujuan pemasarannya. Berdasarkan pengertian tersebut strategi pemasaran dalam penelitian ini adalah polapikir dari pengusaha dalam mengatasi persaingan dan bias membuat pelanggan merasa puas dengan produk yang dijual.

\section{METODE PENELITIAN}

Penelitian ini dilakukan di art shop local Desa Tegallalang, Kabupaten Gianyar.

Adapun ruang lingkup penelitian yang digunakan yaitu Strategi Pemasaran, dalam penelitian ini yaitu strategi yang digunakan perusahaan art shop guna memasarkan dan bertahan dalam kondisi saat ini yang berdasarkanpenerapan aspek internal dan eksternal art shop yang dipadukan dengan menggunakan analisis SWOT.

Penelitian ini jenis dan sumber data yang digunakan dalam penelitian ini adalah jenis data kualitatif seperti uraian kalimat dari hasil wawancara yang disusun secara deskriptif dan sumber data yang digunakan dalam penelitian ini adalah sumber data primer dan sumber data sekunder. Teknik pengumpulan data dalam penelitian ini terdiri dari tiga teknik yaitu: observasi, wawancara semi terstrukstur dan dokumentasi (Sugiyono, 2014). Untuk menentukan informan menggunakan teknik purposive sampling yaitu kepada bendesa adat Tegallalang, pedagang maupun pengusaha art shop, dan Pecalang. Selain itu dalam penelitian ini menggunakan accidental sampling dalam penyebaran kuesioner yaitu wisatawan yang berkunjung ke art shop di Tegallalang.

Dalam penelitian ini menggunakan teknik analisis deskriptif kualitatif. Juliansyah (2011) mendefinisikan analisis deskriptif kualitatif yaitu gejala, peristiwa, kejadian yang terjadi pada saat sekarang sehingga mendapatkan gambaran yang jelas dan objektif mengenai permasalah pada penelitian ini dan mengetahui strategi pemasaran pada art shop lokal yang dipadukan dengan pendekatan analisis SWOT. Analisis SWOT adalah identifikasi dari berbagai faktor secara sistematis untuk merumuskan strategi perusahaan. Analisis ini berdasarkan pada logika yang dapat memaksimalkan kekuatan dan peluang namun secara bersamaan dapat meminimalkan kelemahan dan ancaman. Proses pengambilan keputusan strategis selalu berkaitan dengan pengembangan misi, tujuan strategi dan kebijakan perusahaan. Perencanaan strategis harus menganilisis faktor-faktor strategis perusahaan dalam kondidi saat ini. 


\section{HASIL DAN PEMBAHASAN}

a. Profil art shop di Desa Tegallalang

Desa Tegallalang terletak di kabupaten Gianyar provinsi Bali. Jarak tempuh dari kota Denpasar sekitar 35 km, kira - kira sekitar 1 jam 15 menit dan sekitar $15 \mathrm{~km}$ dari pusat kota Gianyar, dan sekitar $5 \mathrm{~km}$ dari daerah pariwisata Ubud. Di desa Tegallalang terdapat sebuah destinasi pariwisata yaitu dikenal dengan Ceking dan Tegallalang merupakan jalur penghubung (transit) objek wisata Kintamani dengan Pariwisata Ubud. Jadilokasi yang sangats trategis untuk membuka usaha kecil seperti art shop.

Art shop di Tegallalang munculs ekitar tahun 1990, yang didirikan pertama oleh orang local dari sekitaran Tegallalang. Meningkat pesatnya jumlah art shop di Tegallalang terjadi sekitar tahun 2011 namun tidak hanya masyarakat local saja melainkan orang non lokal.

Munculnya art shop di tegallalang dapat memberikan pemasukan kepadadesa Tegallalang dengan mewajibkan pemilik art shop membayar iuran sebesar Rp.25.000. Dana yang terkumpulakan digunakan sebagai menunjang sector pembangunan dan odalan di pura yang terdapat di tegallalang.

b. Strategi Pemasaran Usaha Art shop Lokal di Desa Tegallalang Kabupaten Gianyar

Untuk mengetahui kondisi art shop di Tegallalang saat ini menggunakan analisis SWOT yaitu berdasarkan aspek lingkungan internal dan aspek eksternal dengan menguraikan streng (kekuatan), weaknesses (kelemahan), opportunities (peluang), threats (ancaman).

Berikut ini adalah hasil penelitian berdasarkan analisis SWOT:

1. Strength (kekuatan)

Kekuatan yang terdapat pada art shop di Tegallalang yaitu:

1) Terdapat berbagai jenis produk dengan model yang berbeda beda, salah satu contohnya yaitu lukisan, bingkai, patung dll.

2) Proses pembuatan barang secara langung diperlihatkan di toko, dengan hal tersebut wisatawan dapat menilai langsung kualitas bahan baku ataupun kualitas produk.

3) Terdapat produk yang melambangkan seni dan budaya adat Bali seperti lukisan tari, patung dll.

4) Tegallalang memiliki budaya yang unik dan dapat menarik perhatian wisatawan untuk menyaksikan budaya yang dikenal dengan ngerebeg.

\section{Weaknesses (kelemahan)}

Kelemahan yang terdapat pada art shop di tegallalang yaitu sebagai berikut:

1) Sempitnya laus toko yang menjadikan tidak semua model produk dapat di pajang, menyebakan wisatawan tidak dapat melihat semua model produk,

2) Lambatnya memproduksi produk akibat sulitnya mencari bahan baku dan sulitnya mencari pengerajin.

3) Kurangnya pengetahuan atau kemampuan pedagang dalam berbahasa asing.

4) Pengetahuan atau kemampuan dalam menggunakan teknologi kurang, dimana akan menyebabkan kalah bersaing dengan art shop lain yang memasarkan produknya dengan sistem online.

5) Tidak ada kesepakatan harga dengan art shop lain $\mathrm{di}$ Tegallalang, dimana pemilik art shop berbeda - beda memberi harga kepada pelanggan.

6) Stok atau persedian barang sedikit, hal ini mengakibatkan wisatawan tidak bisa membeli produk dengan jumlah yang banyak tanpa memesan terlebih dahulu. 
7) Tidak terdapat lahan parkir pada masing - masing art shop sehingga mempersulit wisatawan saat berhenti di depan kios.

\section{Opportunities (peluang)}

1) Terdapat objek wisata di Tegallalang yang dikenal dengan nama ceking terrace. Dimana lokasi art shop berada pada kawasan objek tersebut.

2) Berkembangnya sistem teknologi, dimana pengusaha dapat mempermudah dalam memasarkan suatu produk dengan sistem online.

3) Terdapat salauran destribusi seperti cargo dan guide, yang dapat membantu pemilik art shop dalam menjual barangnya dengan memberi persentase komisi yang telah disepakati.

4) Tegallalang sebagai jalur penghubung daerah pariwisata ubud dengan Tampaksiring dan jalur Ubud dengan Kintamani.

5) Seiring dengan kemajuan teknologi yang menciptakan mesin atau alat yang dapat mempermudah dalam proses membuat produk.

4. Threats (ancaman)

1) Menurunnya kualitas produk karena terjadi persaingan harga akibat meningkatnya jumlah art shop yang menjual produk dengan jenis yang sama.

2) Munculnya pasar moderen, hal ini merupakan salah satu faktor menurunnya jumlah penjualan pada art shop.

3) Berkurangnya minat generasi muda untuk menjadi pengerajin, hal ini dapat menyebabkan sulitnya pengusaha mencari kaaryawan sehingga penyelesaian produk lebih lama.
4) Masuknya pasar bebas (MEA) dimana akan muncul pesaing pesaing yang memiliki pemikiran yang cerdas dengan modal yang tinggiuntuk mengungguli art shop lokal.

Dari uraian diatas dapat ditentukan strategi yang dapat digunakan untuk meghadapi persaingan yaitu:

a. Strategi SO (trenght - opportunities)

1. Membuat atraksi wisata yang unik dan mengandung nilai seni atau budaya (S) sehingga mampu menarik perhatian wisatawan untuk berhenti di Tegallalang dengan memanfaatkan Tegallalang sebagai jalur transit (0).

2. Memperlihatkan proses pembuatan produk kepada wisatawan atau membuat produk secara langsung di toko sehingga wisatawan yang berkunjung atau melewati Tegallalang dapat melihat pengerajin membuat produk dengan cara tradisional (S). hal tersebut dapat memanfaatkan keberadaan destinasi pariwisata di Tegallalang yaitu ceking terrace dan Tegallalang merupakan jalur transit antara objek pariwisata Ubud dengan Kintamani (0).

b. Strategi WO (weaknesses - opportunities)

1. Strategi meningkatkan ilmu pengetahuan tentang penggunaan IT atau sistem informasi dengan mengikuti kursus ataupun pelatihan IT (W) agar pedagang mampu mempromosikan produk secara online seiring dengan kemajuan teknologi yang ada (0) sehingga wisatawan dengan mudah mencari informasi mengenai produk yang terdapat pada art shop.

2. Strategi membuat tempat persinggahan dan penyediaan lahan parkir pada masing masing art shop (W) supaya wisatawan dapat beristirahat dalam perjalanannya sehingga mereka mengenal Tegallalang sebagai daerah pengerajin dan mencegah terjadinya kemacetan karena Tegallalang merupakan jalur transit antara Ubud Kintamani (0). 
3. Strategi menyediakan fasilitas - fasilitas yang canggih seperti mesin ataupun yang lainnya seiring dengan kemajuan teknologi saat ini (0) agar dapat mempermudah proses pembuatan produk sehingga produk yang dikerjakan lebih bagus dan waktu penyelesaian produk lebih cepat (W).

c. Strategi ST (strength - threaths)

1. Strategi mencari ide - ide baru undung mengembangkan model produk yang unik dengan tidak menghilangkan nilai seni atau budaya Bali dengan kualitas yang bagus (S) sehingga mampu bersaing antar art shop lain dan produk yang memiliki nilai budaya Bali tetap lestari (T).

2. Strategi membeli bahan baku secara patungan ataupun bekerja sama dengan pengusaha dengan jenis produk yang diproduksi sama, sehingga mampu membeli bahan baku dengan jumlah yang banyak agar mendapat potongan harga (T) sehingga pengusaha tidak menurunkan kualitas bahan baku yang digunakan dan kualitas produk tetap bagus (S).

d. Strategi WT (weaknesses - threaths)

1. Strategi membuat patokan harga secara pasti dan kesepakatan bersama antar art shop lain dengan jenis barang yang sama guna mencegah terjadinya persaingan tidak sehat (W) sehingga pedagang antar art shop lain mampu bersaing dengan sehat tanpa harus menurunkan kualitas produk seperti membuat produk yang kelihatn sama tapi dengan kualitas yang kurang bagus (T).

2. Strategi meningkatkan kemampuan dalam berbahasa asing dengan cara kursus atau latihan berbahasa asing (W) supaya wisatawan mudah berkomunikasi kepada pedagan dan pedagang mampu menjelaskan secara detail tentang produk yang dijual dan mampu menghadapi persaingan dengan masuknya pasar bebas (T).

\section{PENUTUP}

A. Simpulan

Dari uraian diatas strategi pemasaran yang digunakan oleh pengusaha ataupun pemilik art shop utnuk bersaing adalah sebagai berikut

Memperlihatkan proses pembuatan produk kepada konsumen dan dan menciptakan atraksi pariwisata guna menarik wisatawan yang dilihat dari strategi kekuatan dengan peluang(SO).

Strategi mengikuti kursus atau latihan IT supaya mempermudah promosi, menyediakan tempat parkir dan menyediakan peralatan yang canggih seperti mesin untuk pembuatan produk agar pengerajin dapat lebih cepat menyelesaikan produk yang dilihat dari strategi WO (kelemahan dengan peluang).

Strategi menciptakan model - model produk yang unik dan memiliki nilai seni budaya Bali dengan kualitas yang bagus, dan membeli bahan baku secara patungan dengan orang lain agar harga bahan baku lebih murah, yang dilihat dari strategi ST (kekuatan dengan ancaman).

Strategi mengikuti kursus bahasa asing agar pedagang mampu menjelaskan produknya dengan baik dan membuat patokan harga secara pasti ataupun kesepakatan dari pedagang lainnya di art shop Tegallalang, yang dilihat dari strategi WT (kelemahan dengan ancaman)

B. Saran

Dari hasil penelitian, ada beberapa saran dari peneliti kepada pengusaha atau pemilik art shop yaitu:

Bersaing secara sehat dengan membuat produk dengan kualitas produk melainkan dengan menurunkan harga harga barang dengan kualitas yang kurang baik, meningkatkan promosi secara online supaya mampu bersaing dengan pasar modern, dan pedagang harus meningkatkan kemampuan dalam berbahasa asing . 


\section{DAFTAR PUSTAKA}

Chandra, Gregorius. 2002. Strategi dan Program Pemasaran. Edisi 1. Andi. Yogyakarta

Kotler,Philip. John Bowen. James Makens. 1999. Pemasaran Layanan dan Pariwisata:Edisi Dua. Denpasar : Fakultas Ekonomi Universitas Udayana.

Palguna, I Nyoman . 2010. Karakteristik Art shop Dan Persepsi Wisatawan YangBerkunjung Ke Pasar Seni Desa Adat Guwang Kecamatan Sukawati Kabupaten Gianyar.Denpasar : Program Studi D4 Pariwisata Universitas Udayana

Purnamasari. 2016. Strategi Pemasaran Usaha Art Shop Lokal Dalam Menghadapi Persaingan Global Di Lingkungan Batu Belig.

Rangkuti, Freddy. 2015. Teknik Membedah Kasus Bisnis ANALISIS SWOT.

Jakarta : Kompas Gramedia.

Sugiyono, 2014. Metode penelitian kuantitatif, kualitatif dan R\&D. Bandung: Alfabeta.

Vickers, Adrian. 2013. Bali Membangun Kembali Industri Pariwisata : 1950-an

Yuliasih, Eka, 2013. Studi eksplorasi dampak keberadaan pasar modern terhadap usaha ritel waserda dan pedagang pasar tradisional di Kecamatan Klirong Kabupaten Kebumen : program pendidikan ekonomi Universitas Negeri Yogyakarta 